\title{
A propósito de la cronología final del poblado ibérico del Molí d'Espigol (Tornabous, Lleida)
}

M. Cura-Morera e I. Garces

ANTECEDENTES

Las excavaciones arqueológicas en el poblado ibérico del Moli d'Espigol, en el término municipal de Tornabous, a unos $10 \mathrm{kms}$ de la ciudad de Tárrega, se iniciaron en 1970 bajo la dirección de don Antonio Llorens, director del Museo Diocesano de Solsona y antiguo colaborador de don Juan Serra Vilaró, quien había proporcionado a don Manuel Gómez Moreno para su publicación un grafito iberico de dicho yacimiento '. Las excavaciones del Museo Diocesano de Solsona se prolongaron a lo largo de tres campañas hasta 1972, publicándose parte tan solo de la campaña de 1971 en la cual colaboró un equipo del Instituto de Arqueologia y Prehistoria de la Universidad de Barcelona ?

Entre 1975 y 1984 las excavaciones fueron dirigidas por el profesor don Joan Maluquer de Motes, pero lamentablemente sus trabajos no llegaron a publicarse al acontecer el fallecimiento del insigne investigador,

Gomez Moreno, M. La escritura iberica y su lenguaje. Suplemento de Epigrafia iberica. Madrid. 1949.

Maluouer de Motes. J.: Llorens. A.; Baldellou. V.; Junyent. E.. y Cura, M. "Colaboración de la Universidad de Barcelona en las excavaciones del poblado iberico del Moli d'Espigol en Tornabous". Pyrenae. 7. Barcelona. 1971. 
quien tan sólo pudo legarnos una pequeña guia sobre el yacimiento ${ }^{3}$. En 1975, el poblado fue adquirido en propiedad por el Ministerio de Cultura y en 1981 se traspasó su titularidad a la Generalitat de Catalunya.

A partir de 1987 hasta el presente, el Servei d'Arqueologia de la Generalitat de Catalunya ha procedido a un conjunto de campañas de consolidación y restauración de las estructuras visibles a fin de adecuar el yacimiento para su visita. Se trata pues de uno de los grandes yacimientos arqueológicos de Cataluña de época ibérica, pero se halla desproporcionalmente deficitario respecto su documentación en la bibliografía arqueológica ${ }^{4}$.

El poblado ofrece diferentes fases constructivas por tratarse de un verdadero "tell», si bien los restos hoy visibles al período lbérico Pleno, es decir, desde fines del siglo $\vee$ a.C. a principios del siglo $\|$ a.C. Por este motivo los anteriores directores de las excavaciones no dudaron en otorgar la destrucción del poblado al periodo de las crisis bélicas de la Segunda Guerra Punica, ya fuera por parte de Anibal o de los romanos.

No obstante, en un estudio parcial de las cerámicas de barniz negro se revisó su cronologia final quedando bien establecida en torno el año 150 a.C. ${ }^{5}$.

La presente nota tiende pues a concretar con nuevos elementos la cronología final del poblado, teniendo presente la práctica desaparición de los restos urbanos que corresponderian a la última fase, por haber sufrido el solar del yacimiento a fines de la década de los años cincuenta importantes trabajos de nivelación del terreno.

${ }^{3}$ Maluouer, J., Moli d'Espigol. Tornabous, Guia del jaciment, Generalitat de Catalunya, Barcelona, 1986.

${ }^{4}$ CURÁ, M.. "Acerca de unas cerámicas grises con decoración estampillada en la Catalunya prerromana", Pyrenae. 7, Barcelona, 1971.-JUNYENT, E., "Acerca de la ceramica de barniz rojo aparecida en el área ilergeta", Pyrenae 10. Barcelona, 1974.-Gracia, F.. "Las influencias mediterraneas y el momento de plena formación de la cultura ibérica en Cataluna" (Las cerámicas aticas y de barniz negro del poblado iberico del Moli d'Espigol. Tornabous. Urgell), Tesis doctoral. Universidad de Barcelona, 1986.-CuRA-Morera. M., "Notes sobre el poblat prerroma del Moli d'Espigol (Tornabous, Urgell)", VIII Col.loqui Internacional d'Arqueologia de Puigcerdà. Puigcerdà, 1988 (en prensa).

${ }^{5}$ Gracia, F., "Precisiones sobre la cronologia del momento final del poblado ibérico del Molí d'Espigol", VII Colloqui Internacional d'Arqueologia de Puigcerdà. Puigcerdà, 1986 (1988). 


\section{A propósito de la cronología final del poblado ibérico del Moli d'Espigol}
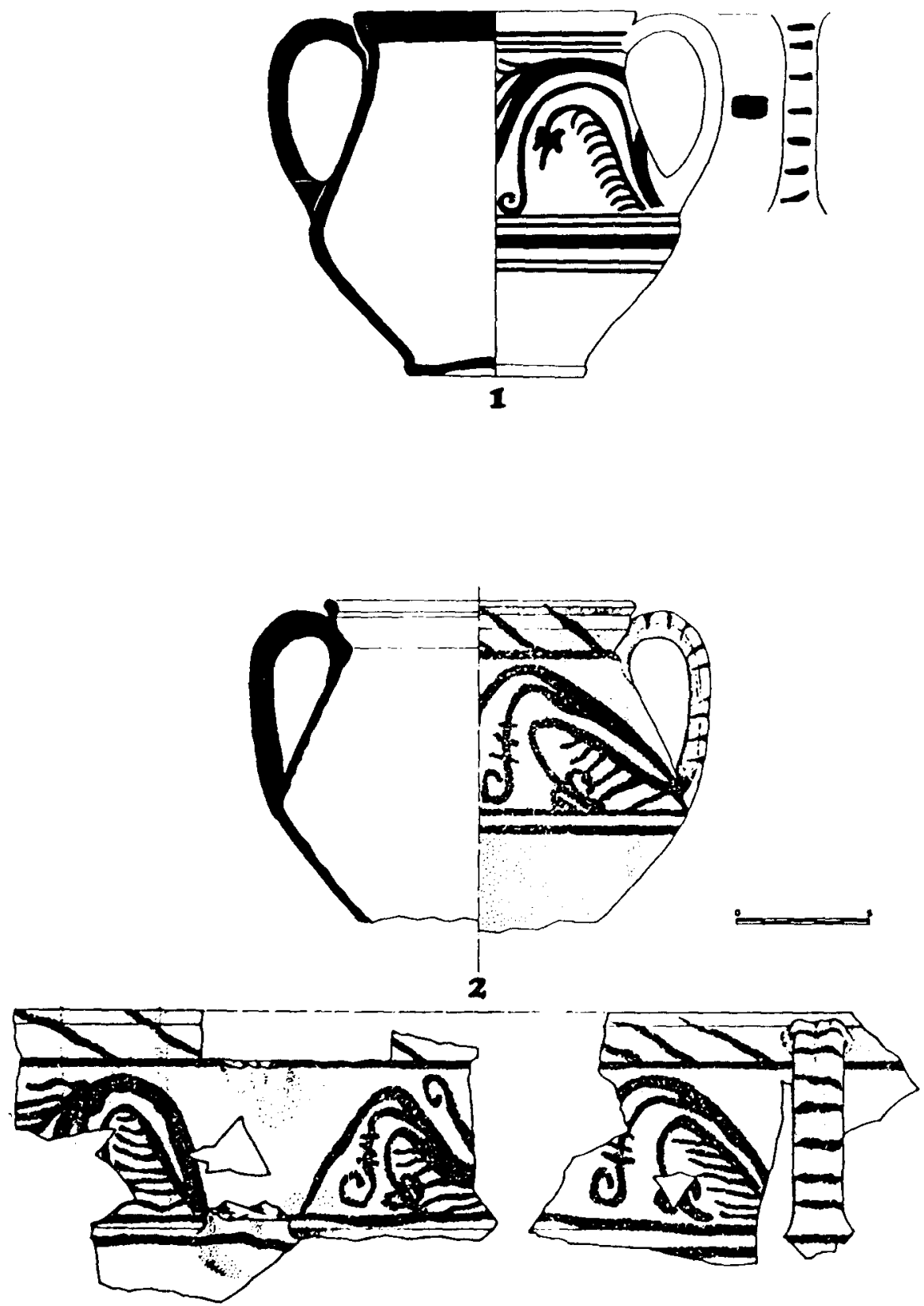

Fig. 1. Jarritas bicónicas tardo-ibéricas: 1, Moli d'Espigol. 2, La Paeria. 


\section{LA ESTANCIA NÚM. 90}

Esta estancia pertenece al barrio adosado al paramento interno de la muralla en el sector occidental, y corresponde a la última estancia en que se realizaron los trabajos de consolidación durante la campaña de 1989. La estancia había sido excavada por el profesor Maluquer de Motes, pero dejando en su interior y en sentido longitudinal un testimonio de un metro de anchura; con los años, el testimonio quedó afectado por la erosión, motivo por el cual se procedió a su excavación.

A unos $20 \mathrm{~cm}$ de la superficie del terreno se localizó un nivel de habitación, hallándose una jarrita de forma bitroncocónica provista de asas y pintada con motivos vegetales muy esquematizados (fig. 1.1). Dicha vasija correspondería sin duda a una pieza tardia dentro del contexto tradicional del yacimiento ofreciendo a su vez el primer testimonio en estratigrafía de la última fase del poblado ${ }^{6}$.

Por ello procedimos a localizar el resto de elementos cerámicos aparecidos en esta estancia en campañas anteriores y atribuidos a su nivel superficial, constatando que entre los materiales muy fragmentados se hallaran un par de fragmentos de la jarrita en cuestión y una base de la forma Lamboglia 1 de campaniense $B$, elemento hasta el momento no detectado en el yacimiento.

\section{FILIACIÓN Y PROPUESTA CRONOLÓGICA}

Para despejar dudas acerca de la «modernidad» de la jarrita en cuestión con respecto a los ejemplares ya conocidos del Moli d'Espigol, además de considerarse su posición estratigráfica y su asociación a campaniense $B$, pueden retenerse tres observaciones: la técnica de fabricación, la forma y los aspectos estilisticos en la decoración. La primera consiste en añadir un engobe rojo no espeso que cubre la superficie exterior y parte del cuello por el interior, solución desconocida en los vasos ilergetes de los siglos III y II a.C., que entronca directamente con las producciones de cerámica común romana del Valle del Ebro en el

Cura-Morera, M., Notes sobre el poblat..., obra citada. nota 10. 
siglo 1 a.C. ${ }^{7}$ y que consideramos pervive en el । d.C. ${ }^{8}$; la segunda es también clara novedad de la primera centuria antes de la Era, y finalmente, la técnica decorativa en pintura floral a base de pequeñas hojas en tinta plana dispuestas al final de esquemáticos tallos florales, difiere en mucho de las grandes hojas exentas que caracterizan los vasos pintados del Tossal de les Tenalles de Sidamon ${ }^{9}$ y de Margalef (Torregrossa) ${ }^{10}$.

El conocimiento de la cerámica ibérica tardía en tierras de Lleida, aquella que coincide con el decidido proceso romanizador, ha comenzado paradójicamente en fecha muy reciente a pesar de sus manifiestas posibilidades. Puede decirse sin exageración que apenas contamos con conjuntos posteriores al 100 a.C. hasta la publicación de los ejemplares de yacimientos rurales romanos próximos a lierda de la Fonteta de Grealó ${ }^{11}$ y Raimat ${ }^{12}$.

Este panorama ha cambiado notablemente con las intervenciones urbanas en la ciudad de Lleida a mediados de la década de los ochenta. Las excavaciones practicadas por E. Junyent y A. Pérez Almoguera, del Estudi General de Lleida, en el solar de La Paeria o Ayuntamiento aportan una secuencia estratigráfica inédita aún, pero conocida por algunos avances ${ }^{13}$ que permiten individualizar un momento concreto a grandes rasgos entre el 90 y 70 a.C., y otro posterior hasta el cambio de Era, al que pertenece una jarrita bicónica afín a la aquí tratada (fig. 1.2). En el mismo yacimiento existen un total de doce fragmentos diferentes que

Amare, M. T., "Avance al estudio de un posible alfar romano en Tarazona: II, Cerámicas engobadas no decoradas", Turiaso, V. Tarazona, 1984.-AGuarod. M. C.. Producciones engobadas en el municipium Calagurritano, a Calahorra. Bimilenario de su fundacion. Madrid. 1984.

"Garces. 1., "La ceramica iberica pintada". a Perez Almoguera, A. (ed.): Els materials del jaciment romà de Raimat, Lleida. Lleida, 1988.

3 C. Serra Rafols, J. de, y Colominas, J., Corpus Vasorum Antiquorum. Espagne. Musée Archéologique de Barcelone. Barcelona, 1958-65. PeLLICER, M., "El Tossal de les Tenalles de Sidamunt y sus ceramicas pintadas". Archivo Español de Arqueologia, XXXIX. Madrid, 1966.

10 JUNYENT. E., "Los materiales del poblado ibérico de Margalef, en Torregrossa (Lerida)". Pyrenae 8, Barcelona, 1972.

iJ Junyent, E., y Perez Almoguera, A.. "El yacimiento romano de la Fonteta de Grealó (Lleida, Segria)", Merda. XLIII, Lerida, 1982.

12 GARCES, I., "La cerámica iberica pintada...". obra citada.

13 Junyent, E., y Perez Almoguera, A., "Noves dades sobre la ciutat tomana d'llerda", Tribuna d'Arqueología 1982-83. Barcelona, 1983. Junyent, E., y PEREz Almoguera. A.. El Museu de la Paeria. Lleida. 1983. Gallart, J.: Junyent. E.: Perez. A., y Rafel, N.. L'Arqueologia a la ciutat de Lleida (1975-1985). Lleida, 1985. Junyent, E. Perez. A., y Rafel. N., "Notes a l'arqueologia de la ciutat", Cota Zero. 1, Vic, 1985. 
corresponden a bordes o carenas de jarritas, algunas con barniz rojo combinado con la pintura morado-vinosa.

La individualización de este tipo de vasos (nuestra forma 3 de un reciente trabajo) ${ }^{14}$ nos ha llevado a reconocerlos en otros yacimientos ilerdenses que, aunque carezcan de contexto estratigráfico preciso por proceder de superficie o tratarse de antiguas excavaciones, siempre aparecen vinculados a importaciones que cubren el siglo I a.C. y se adentran en el I d.C. Entre ellos se documentan restos de seis vasos en el Antiguo Portal de La Magdalena de Lleida, un ejemplar completo en el poblado ibérico de Gebut (Soses) y que debe corresponder también a su último momento, otro incompleto en el poblado de La Fita (Juneda) y dos posibles trozos de carena en Raïmat, únicos no inéditos ${ }^{15}$. Geográficamente, la pieza del Molí d'Espigol se convierte en el hallazgo más oriental conocido.

Respecto a las semejanzas formales, sin ser estrictamente concluyentes para este tipo de producción a medio camino entre la artesania creativa y una cierta industrialización que acompaña y que imponen las producciones romanas, nuestro vaso presenta todavía líneas en el cuello en lugar de trazos oblicuos en serie, y en la carena una banda entre parejas de lineas finas bien delimitadas, aspectos que personalmente creemos son indicativos de la antigüedad del vaso del Molí d'Espigol dentro de la seriación formada por sus paralelos y que encaja mejor en una cronología de la primera mitad del siglo I a.C.

${ }^{14}$ Garces, I., Assimilació, resistència i canvi a la romanització en el món ilerget. Tesis doctoral inédita presentada en el Estudi General de Lleida en octubre de 1990.

is GaRCES, I.. "La cerámica ibérica pintada...". obra citada. 